\title{
Uses and Gratifications of Problematic Social Media Use Among University Students: a Simultaneous Examination of the Big Five of Personality Traits, Social Media Platforms, and Social Media Use Motives
}

\author{
Kagan Kircaburun $^{1}$ • Saleem Alhabash ${ }^{2}$. \\ Şule Betül Tosuntaș ${ }^{3}$ Mark D. Griffiths ${ }^{4}$
}

Published online: 15 May 2018

(C) The Author(s) 2018

\begin{abstract}
Recent studies suggest that users' preferences of social media use differ according to their individual differences and use motives, and that these factors can lead to problematic social media use (PSMU) among a minority of users. The objectives of the present study were to investigate the influences of (i) demographics and Big Five personality dimensions on social media use motives; (ii) demographics and use motives on social media site preferences; and (iii) demographics, personality, popular social media sites, and social media use motives on PSMU. The sample comprised 1008 undergraduate students, aged between 17 and 32 years ( $M=20.49, \mathrm{SD}=1.73 ; 60.5 \%$ women). The participants completed a questionnaire comprising the Social Media Use Questionnaire, Social Media Usage Aims Scale, and Ten-Item Personality Inventory. Multiple linear and hierarchical regression analyses showed that social media use motives of (i) meeting new people and socializing, (ii) expressing or presenting a more popular self, and (iii) passing time and entertainment were associated with problematic
\end{abstract}

Mark D. Griffiths

mark.griffiths@ntu.ac.uk

Kagan Kircaburun

kircaburunkagan@gmail.com

Saleem Alhabash

sa@msu.edu

Şule Betül Tosuntaș

sbtosuntas@hotmail.com

Faculty of Education, Duzce University, Duzce, Turkey

2 Advertising and Public Relations, Michigan State University, East Lansing, MI, USA

3 Faculty of Education, Uludağ University, Bursa, Turkey

4 International Gaming Research Unit, Psychology Department, Nottingham Trent University,

Nottingham, UK 
social media use. Moreover, participants that preferred Instagram, Snapchat, and Facebook reported higher scores of problematic social media use. Finally, being female, introverted, conscientious, agreeable, and neurotic were associated with PSMU. The findings offer empirical evidence for uses and gratifications theory because the findings demonstrated that (i) different personality traits predict different motives, (ii) different motives predict preference of different platforms, and (iii) different individual differences such as personality, preference of platform, and specific use motives predict PSMU.

Keywords Problematic social media use - Social media use motives - Big Five personality · Social media sites $\cdot$ Daily technology use

The use of social media sites (SMSs) has become one of the most popular social behaviors, thanks to the ubiquity and many different opportunities that they offer. Recent statistics suggest that more than two-thirds of the internet users and approximately one-third of the people living in the world are SMS users (Kemp 2017a, b). SMSs have been defined as "web-based services that allow individuals to (1) construct a public or semi-public profile within a bounded system, (2) articulate a list of other users with whom they share a connection, and (3) view and traverse their list of connections and those made by others within the system" (Boyd and Ellison 2007, p. 211). While there are various motivations for individuals to use SMSs (Alhabash and Ma 2017; Haridakis and Hanson 2009; Khan 2017; Whiting and Williams 2013), the primary motivations include establishing and maintaining online and offline relationships (Kuss and Griffiths 2011, 2017; Young 2015).

Research has demonstrated that SMS uses and gratifications vary as a function of user characteristics, such as age, gender, and personality. The uses and gratifications can also depend on the type of SMS engaged in. For example, Facebook can be used to satisfy the need to belong and for self-presentation (Nadkarni and Hofmann 2012); Instagram can be used for self-expression and social interaction (Lee et al. 2015), surveillance/knowledge about others, documentation, coolness, and creativity (Sheldon and Bryant 2016); and Snapchat can be used for communication with the immediate environment (Piwek and Joinson 2016). Uses and Gratifications Theory (U\&GT; Katz et al. 1973) helps explain the gratifications sought and obtained in the use of social media, and also shows that these gratifications differ according to individual characteristics.

There is limited research on the problematic use of social media based on U\&GT (Floros and Siomos 2013; Wan 2009) which has only recently been applied with regard to SMSs. Consequently, it is not known which gratifications of social media use underlie problematic social media use. There are very few studies investigating the relationship between personality and Facebook use motives (Horzum 2016), or between Facebook use motives and Facebook addiction in Turkish undergraduates (Koc and Gulyagci 2013). Therefore, the aim of the present study was to investigate the relationships between gender, age, popular SMSs, gratifications in the use of social media, personality differences, and problematic social media use (PSMU). Firstly, the predictive role of demographics and Big Five personality traits on social media use motives were examined. Secondly, demographics and social media use motives were used to predict preference of popular social media sites. Finally, all these variables were examined hierarchically in order to explain PSMU. The importance of the present study is that it is the first to examine the relationship between social media use motives and PSMU while controlling for demographics, personality differences, and popular SMSs 
among university students. Problematic use of technological platforms such as SMSs have been shown to be prevalent among university students and associated with impaired psychological wellbeing (Satici 2018), and determining the underlying factors that are associated with PSMU is important in order to prevent its occurrence.

\section{Social Media Sites}

The most popular and commonly known social media sites (SMSs) in the Western world are Facebook, Whatsapp, Twitter, Instagram, Snapchat, Youtube, and Google (Alexa 2017). In this section, a description of each of the SMSs included in the present study (and relevant to the U\&GT literature) is provided.

Facebook is the most popular and top-visited SMS (Alexa, 2017). It had over 2 billion users by 2017 and is actively used by 1.3 billion users every day (Facebook 2017). With a high number of users, Facebook appeals to users of all ages. Facebook has gone beyond the organization's initial goal of finding old friends by constantly developing its capabilities (Junco 2013) such as sharing photos or videos, commenting, creating stories, updating status, private messaging, tagging, and, more recently, broadcasting live streams. Users can also engage in other activities via the Facebook platform including gambling and gaming (Griffiths 2014, 2015). Previous studies investigating the motivations of Facebook use from the U\&GT perspective have reported entertainment, self-expression, information sharing, medium appeal, self-documentation, and socialization (Alhabash et al. 2014; Krause et al. 2014; Smock et al. 2011). Therefore, it is hypothesized in the present study that Facebook use will be associated with maintaining existing relationships, expressing or presenting a more popular self, and entertainment, as well as informational and educational motives.

Whatsapp was developed as an alternative to standard messaging. Currently, it meets the communication needs of more than one billion people (Whatsapp 2017). At present, Whatsapp supports voice and video calling, and the sending and receiving of many different types of media such as text, photos, videos, documents, and locations. It also provides the ability to create stories as social media applications (Whatsapp 2017). Whatsapp and other messaging applications make it easier for individuals to communicate more readily and better fulfill the fundamental need for relatedness (Karapanos et al. 2016). In this context, it can be said that Whatsapp supports communication with the existing neighborhood and does not have the uses to help make new friends. In the present study, it is hypothesized that Whatsapp use will be associated with maintaining existing relationships as well as informational and educational motives.

Twitter, one of the most popular microblogging sites in the world, currently has 330 million active users per month (Statista 2018). On Twitter, individuals can read and post tweets with a maximum of 280 characters. According to research, Twitter has been used for information sharing, social interaction, information seeking, mobilization, content, and new technology gratifications (Johnson and Yang 2009; Liu et al. 2010). It is commonly used in many countries to spread and follow important news and developments (Zhao et al. 2011). Previous studies investigating Twitter use from the U\&GT perspective have reported different features of Twitter (e.g., retweets, replies, likes, etc.) were associated with the gratification of need to connect to other Twitter users (Chen 2011). In the present study, it is hypothesized that Twitter use will be associated with meeting new people and socializing, expressing or presenting a more popular self, as well as informational and educational motives. 
Instagram has 800 million active users (Instagram 2017). Instagram is the fastest growing SMS (Wagner 2015) due to the rapid growth in its popularity among teenagers and young adults (Alhabash and Ma 2017; Jackson and Luchner 2017). Instagram allows users to take, filter, and share photos, and allows live broadcast and story creation with later added features. In terms of self-presentation - which is one of the gratifications obtained for using SMSs Instagram provides a very suitable environment for individuals. Previous studies investigating Instagram use from the U\&GT perspective have reported different motivations such as entertainment, convenience, self-expression, medium appeal, interpersonal interaction, surveillance, documentation, coolness, and creativity (Alhabash and Ma 2017; Sheldon and Bryant 2016). In the present study, it is hypothesized that Instagram use will be associated with expressing or presenting a more popular self, passing time, entertainment, and task management motives.

Snapchat is an instant messaging application that allows its users to send photos or short videos (called snaps). Users can determine how long the submitted snapshots can be viewed, and can create unlimited stories for $24 \mathrm{~h}$ (Alhabash and Ma 2017). Snapchat is known to have more than 100 million users (Piwek and Joinson 2016), and is the third most popular SMS after Facebook and Instagram (Duggan 2013; Utz et al. 2015). The use of Snapchat is often seen as fun (Katz and Crocker 2015; Piwek and Joinson 2016) and it is used to communicate with the immediate community (Vaterlaus et al. 2016). Previous studies investigating Snapchat use from the U\&GT perspective have reported different motivations such as entertainment, convenience, medium appeal, self-expression, modality, agency, interactivity, navigability, and privacy (Alhabash and Ma 2017; Stanley 2015). In the present study, it is hypothesized that Snapchat use will be associated with maintaining existing relationships and expressing or presenting a more popular self.

YouTube is ranked second in the ranking of all websites visited on the Internet, and ranked first among video sites (Alexa 2017). It serves a very broad audience, both amateur and professional (Xu et al. 2016). Every user can rate (like/dislike), upload videos, and can comment on and share them. It allows users to interact with the site using methods such as rating, video uploading, commenting, and sharing (Khan 2017). There are also numerous videos based on the self-promotion and selfbroadcasting culture (Burgess and Green 2009). YouTube offers a wide variety of opportunities for individuals in the form of active and passive participation, and has achieved previously unthought of levels of social interaction and participation (Khan 2017). Previous studies investigating YouTube use from the U\&GT perspective have reported different motivations such as content creation and viewing, social gratification, relaxing entertainment, social interaction, and information seeking (Balakrishnan and Griffiths 2017; Haridakis and Hanson 2009; Khan 2017). In the present study, it is hypothesized that YouTube use will be associated with passing time and task management, as well as entertainment, and informational and educational motives.

Google+, an SMS operated by Google, offers instant messaging, video-conferencing, grouping friends to allow content sharing, and engaging people with similar interests (Google+ 2017). Google+ is viewed as a mix of the features of Facebook and Twitter, but it is more akin to Twitter because of the unidirectional flow (Curran et al. 2012). Naturally, Google+ finds it difficult to compete with many popular social networking sites, and little research concerning SMSs has focused on Google+. Nevertheless, because of its wide usage for education and information (e.g., Google Drive), in the present study it is hypothesized that Google+ use will be associated with informational and educational motives. 


\section{Uses and Gratifications}

The uses and gratifications theoretical approach (U\&GT) was developed to evaluate user motivations and gratifications of a specific media (Katz et al. 1973). U\&GT has four major assumptions: (i) media use is goal-directed or motivated, (ii) people use media to satisfy their needs and desires, (iii) social and psychological factors mediate media use, and (iv) media use and interpersonal communication are related (Rubin 1993). According to U\&GT, users of media are motivated by two different types of gratifications; gratifications sought and gratifications obtained. Gratifications sought refer to users' expectations of the types of gratifications they would get from using media, whereas gratifications obtained refers to the needs satisfied by media use (Katz et al. 1973; Rubin 1993). Social media sites are considered as important platforms tool for maintaining existing relationships, receiving recent activity news, and obtaining a large network with relatively little effort. Moreover, individuals use social media to obtain gratifications such as passing time, sociability, and social information (Quan-Haase and Young 2010). Both gratifications sought and obtained from a particular medium (i.e., use motivations) influence the selection, frequency, and intensity of using that medium. Motivations and expectations of the gratifications acquired through media use are shaped by numerous individual-level, social, economic, cultural, and political factors. While lower life satisfaction and higher interpersonal utility are associated with individuals' interest in Internet use, feeling valued by friends and family and information-seeking are associated with higher Internet satisfaction (Papacharissi and Rubin 2000). The present study focused on the seven different gratifications for social media use and their relationship with the selection of different SMSs use and problematic social media use (PSMU): (i) maintaining existing relationships, (ii) meeting new people and socializing, (iii) expressing or presenting more popular self, (iv) passing time, (v) entertainment, (vi) as a task management tool, and (vii) informational and educational use motives (Horzum 2016).

PSMU is a complex phenomenon and is influenced by many factors and has been conceptualized in various ways (Bányai et al. 2017), including as being sub-type of internet addiction (Griffiths et al. 2014; Young 2015). Similar to behavioral and chemical addictions, people with PSMU show uncontrolled and compulsive behaviors (Griffiths 2005, 2010). From the biopsychosocial model perspective, PSMU in its most extreme cases can display the symptoms that are associated with chemical and other behavioral addictions; tolerance, salience, mood modification, withdrawal, conflict and relapse (Griffiths 2005).

In the literature, PSMU has been investigated in relation to specific SMSs such as Facebook (Andreassen et al. 2012; Hong et al. 2014), Twitter (Davenport et al. 2014; Kircaburun 2016a; Kim et al. 2008), Instagram (Kircaburun and Griffiths 2018a, b), Snapchat (Punyanunt-Carter et al. 2017), WeChat (Hou et al. 2017), Youtube (Balakrishnan and Griffiths 2017), and social media in general (Andreassen et al. 2017; Bányai et al. 2017; Kircaburun 2016b; Kircaburun et al. 2018a, b). These studies have shown that PSMU is associated with various psychological, personality, and individual difference factors. Moreover, a few studies that have used U\&GT framework in order to investigate the relationship between social media use motives and social media addiction suggest that entertainment, diversion and self-presentation, seeking friendship, relationship maintenance, and escapism motives and gratifications are associated with social media addiction and more frequent use (Chen and Kim 2013; Floros and Siomos 2013; Huang 2011; Koc and Gulyagci 2013). Based on the aforementioned studies, it is hypothesized that social media use motives, especially social gratifications, self-presentation, and passing time, will be associated with PSMU. 


\section{Uses and Gratifications of Social Media Sites}

A great deal of research has focused on the use of SMSs and the effects of many characteristics such as age, gender, and personality. U\&GT developed to understand how and why traditional media are used (Katz et al. 1973), and has been applied to study the use of SMSs. As noted above, some of the gratifications identified in the literature include social interaction, information seeking, entertainment, passing time, relaxation, communication, convenience, surveillance or knowledge about others, and self-status seeking (Alhabash and Ma 2017; Haridakis and Hanson 2009; Khan 2017; Whiting and Williams 2013). However, little is known about which of these individual gratifications related to SMS use cause PSMU. Therefore, present study investigated the extent to which specific social media use motives and gratifications are related to popular SMSs and PSMU.

Within U\&GT, previous studies have examined the effects of gratifications both sought and obtained in the selection of different SMSs. For instance, one study found that Instagram and Snapchat use intensity was higher than Facebook and Twitter use intensity among university students (Alhabash and Ma 2017). The same study reported that entertainment was the strongest predictor of Facebook, Twitter, Instagram, and Snapchat use intensity. It was also found that self-documentation was related to the intensity of Facebook and Instagram use, and convenience was associated with a higher intensity of Twitter and Snapchat use (Alhabash and Ma 2017). Other studies have found that individuals use Instagram for the gratifications of surveillance, documentation, coolness and creativity (Sheldon and Bryant 2016). Snapchat has been found to be used for obtaining the gratification of maintaining close relationships with friends and family (Piwek and Joinson 2016). Similar to Snapchat, Facebook has also been found to keep up with close and distant friends, for informational and educational gratifications, passing time, and for self-promotion (Manasijević et al. 2016; Sendurur et al. 2015). Finally, activities such as reading comments, viewing, liking, disliking, and sharing videos on Youtube have been found to be associated with the gratification of relaxing entertainment (Khan, 2017).

Based on the aforementioned literature, it is hypothesized in the present study that different SMSs use will be associated with specific social media use motives. Although problematic uses of specific SMSs have been examined, it is not known whether preference of a specific platform leads to PSMU in general. However, the motivations to use popular SMSs that are associated with PSMU may also predict students' levels of PSMU. Therefore, the question of whether different SMSs uses are associated with PSMU was examined.

\section{"Big Five" Personality Dimensions}

Personality is considered as an important individual difference that affects media use motivations and gratifications (Rubin 1993). Personality can be described as a dynamic system that generates characteristic patterns such as the behavior, thoughts, and feelings of the individual (Allport 1961). The present study examines personality in terms of the globally accepted Big Five personality dimensions (McCrae et al. 1998). The Big Five personality traits comprise agreeableness, conscientiousness, extraversion, neuroticism, and openness to experience, and relates to the following features (McCrae and John 1992): being reliable, generous, wellmannered (agreeableness); conscientious, hardworking, well-organized, punctual, trustworthy (conscientiousness); talkative, sociable, active, and passionate (extraversion); short-tempered, whiny, unstable (neuroticism); and curious, imaginative, original, unique, with a wide range of interests (openness to experience). 
Previous studies have reported the relationship between personality differences and SMS use and PSMU. For instance, neurotic SMS users are more inclined to engage in self-disclosure (Kuss and Griffiths 2011), are more involved in others' responses to their selfies (Choi et al. 2017), spend more time on Facebook (Moore and McElroy 2012), and engage in social media more passively (Ryan and Xenos 2011). Extraverted individuals use social media for the gratifications of meeting new people and socializing, informational and educational gratifications, and as a task management tool (Horzum 2016). They also post higher numbers of photos and selfies (Kim and Chock 2017), have a higher number of online friends (Amichai-Hamburger and Vinitzky 2010), and they tend to demonstrate higher self-disclosure (Misoch 2015). Agreeableness has been found to positively relate with gratifications of maintaining existing relationships and informational and educational gratifications, and to negatively relate with expressing or presenting a more popular self and entertainmental gratifications (Horzum 2016). Agreeable individuals are more involved in others' and own shared content with "likes" and comments (Choi et al. 2017). Conscientious individuals use social media for the gratifications of maintaining existing relationships, and tend to involve others' responses to their selfies (Choi et al. 2017), whereas unconscientious individuals use social media more for news and information (Ryan and Xenos 2011). Finally, openness to experience has been negatively associated with demonstrating oneself as being more popular on Facebook (Horzum 2016) and selfie-related interactions with others (e.g., uploading selfies, liking or commenting on others' selfies, or receiving likes and comments to the uploaded selfies from others) (Choi et al. 2017). Individuals who are more open to experiences also share more information about themselves on social media (Amichai-Hamburger and Vinitzky 2010).

Research has also shown association between the Big Five personality traits and PSMU. Neuroticism, introversion, and unconscientiousness have been associated with higher problematic use of Facebook (Marino et al. 2016). Another study reported that, when controlled for gender, disagreeableness, unconscientiousness, and introversion were positively associated with problematic use of Twitter (Kircaburun 2016a). Based on the existing literature, it is hypothesized in the present study that lower agreeableness, lower extraversion, lower conscientiousness, lower openness to experience, and higher neuroticism will be associated with PSMU. Moreover, it is hypothesized that more agreeable, extraverted, conscientious, and open to experience (as well as less neurotic individuals) will use SMSs more for maintaining existing relationships, and informational and educational motives, and less for expressing or presenting a more popular self, passing time, and entertainment.

\section{The Present Study}

The present study investigates the relationship between demographics, personality, and social media use motives. Moreover, the study examines the relationship between demographics, Big Five personality traits, SMS use motives, and PSMU. U\&GT is used to explain the underlying motives for SMS use, as has been the case with previous research (Katz et al. 1973). Since an individual's motivation to use SMSs can be a factor in becoming problematic (Kuss and Griffiths 2011, 2017), the relationship between SMS usage and PSMU are investigated. Indeed, since there are so few studies in this area in the literature, examination of the most commonly used SMSs will contribute significantly. At the same time, it is emphasized that the motivation underlying the use of each platform may be different because the majority of the research to date concentrates on Facebook use (Ryan et al. 2014). It is important to explain the use of both SMS use in the context of U\&GT and to determine which use motives and gratifications lead to 
the PSMU. Similarly, according to the U\&GT approach, personality traits also motivate and provide gratification for individuals (Sheldon and Bryant 2016) and for PSMU (Kircaburun 2016a; Kircaburun and Griffiths 2018a). Consequently, it is beneficial to consider PSMU in a more comprehensive way, in terms of the demographic differences, personality dimensions, most popularly used SMSs, and social media uses and gratifications. Therefore, several hypotheses (outlined throughout this introduction) were constructed based on the current literature.

\section{Method}

\section{Participants and Procedure}

Prior to the examination of the variables, the Social Media Use Questionnaire (SMUQ) was adapted into Turkish in a pilot study comprising 68 students (44\% women; $M=20.84$ years, $\mathrm{SD}=3.76$ ). Prior to data collection, the SMUQ was translated to Turkish by the first author using a standardized back translation process (Beaton et al. 2000). In the second phase, a convenience sample of 1008 students, aged between 17 and 32 years $(M=20.49, \mathrm{SD}=1.73)$, from a Turkish state university completed a paper-and-pencil questionnaire (60.5\% women). Data were collected by visiting separate classes and explaining the context of the study and handing out the questionnaires. All participants gave their informed consent and participated in the study voluntarily and anonymously.

\section{Measures}

\section{Demographics}

Participants were asked about their gender, age, daily internet use time, daily mobile phone use time, and social media sites/apps they mostly used (dummy coded). They were asked to select the three most frequently used social media sites/apps from a list of seven social media platforms (i.e., Whatsapp, Instagram, Youtube, Facebook, Snapchat, Google+, and Twitter).

\section{Social Media Use Questionnaire}

The SMUQ was developed by Xanidis and Brignell (2016) and adapted into Turkish by the researchers. The scale comprises nine items (e.g., "I struggle to stay in places where I will not be able to access SNSs [social networking sites]", "I spend a large proportion of the day using SNSs") that are rated on a five-point Likert-type scale examining two subfactors (i.e., withdrawal and compulsion). The SMUQ was used in order to assess students' levels of problematic social media use. Confirmatory factor analysis generated mostly good fit for the two-factor structure $\left(\chi^{2} /\right.$ $\mathrm{df}=1.34, \mathrm{RMSEA}=.07, \mathrm{CFI}=.98, \mathrm{NFI}=.92, \mathrm{GFI}=.91)$. Confirmatory factor analysis $(\mathrm{CFA})$ with the main sample $(N=1008)$ also confirmed the valid structure of the scale. Cronbach's alpha of the Turkish form of the scale in the pretest study was .90. In the present study, it was .87 .

\section{Social Media Usage Aims Scale}

The Social Media Usage Aims Scale (SMUAS) was developed by Horzum (2016) for assessing Facebook use motives and in the present study it was used by replacing the word "Facebook" in 
the title of the scale with "Social Media." There are no items specifically relevant to Facebook in the scale and the word "Facebook" is not present in any of the items (only in the title of the scale). The SMUAS comprises 30 items on a five-point Likert-type scale examining 7 subfactors: (1) maintaining existing relationships (e.g., "I use social media to stay in touch with friends or people I know"); (2) meeting new people and socializing (e.g., "I use social media to meet new friends"); (3) making, expressing, or presenting a more popular oneself (e.g., "I use social media to be cool"); (4) passing time (e.g., "I use social media to occupy my time"); (5) as a task management tool (e.g., "I use social media to store and organize photographs"); (6) for entertainment (e.g., "I use social media to listen music"); and (7) for informational and educational (e.g., "I use social media to keep abreast of current events"). In order to confirm construct validity of the scale, CFA was carried out and generated acceptable fit to the data $\left(\chi^{2} /\right.$ $\mathrm{df}=4.13$, RMSEA $=.06, \mathrm{CFI}=.90, \mathrm{NFI}=.88, \mathrm{GFI}=.90)$. Reported Cronbach's alphas for the total scale and subfactors were $.91, .80, .79, .85, .79, .83, .82$, and .84 respectively (Horzum 2016). In the present study, they were $.89, .76, .72, .64, .82, .78, .64$, and .81 respectively.

\section{Ten-Item Personality Inventory}

The Ten-Item Personality Inventory (TIPI) was developed by Gosling et al. (2003) and adapted to Turkish by Gunel (2010). The inventory comprises the Big Five personality dimensions which are neuroticism (e.g., "I see myself as anxious, easily upset"), extraversion (e.g., "I see myself as extraverted, enthusiastic"), conscientiousness (e.g., "I see myself as dependable, selfdisiplined"), agreeableness (e.g., "I see myself as critical, quarrelsome"), and openness to experience (e.g., "I see myself as open to new experiences, complex"). Each dimension has two items on a 5-point Likert scale. Cronbach's alphas for the dimensions were reported between .70 and .89 for the Turkish form of the scale. The highest scored dimension is considered as the dominant personality trait of the individual.

\section{Statistical Analysis}

The present study used descriptive statistics, regression analysis, and confirmatory factor analysis (CFA). The statistical analyses were carried out with SPSS 23 and AMOS 23 software. In the CFA, maximum likelihood estimation method was used. Furthermore, goodness of fit indices designated by $\mathrm{Hu}$ and Bentler (1999) were utilized. Consequently, thresholds for good and acceptable fit values are as follows: root mean square residuals (RMSEA) $<.05$ is good, standardized root mean square residuals (SRMR) $<.05$ is good, Comparative Fit Index $(\mathrm{CFI})>.95$ is good, Normed Fit Index (NFI) $>.95$ is good, Goodness of Fit Index $(\mathrm{GFI})>.95$ is good, also RMSEA $<.08$ is acceptable, SRMR $<.08$ is acceptable, CFI $>.90$ is acceptable, NFI $>.90$ is acceptable, GFI $>.90$ is acceptable.

\section{Results}

Descriptive statistics (Table 1) show that $14 \%$ of the participants used the internet less than $2 \mathrm{~h}$ daily and that $44 \%$ had used the internet more than $4 \mathrm{~h}$ daily. Similarly, $13 \%$ of the participants used mobile phones less than $2 \mathrm{~h}$ daily and $51 \%$ had used mobile phones more than $4 \mathrm{~h}$ daily. The most frequently used social media platforms among participants were as follows (Table 1): Whatsapp (92\%), Instagram (79\%), Youtube (78\%), Facebook (55\%), Snapchat (37\%), 
Table 1 Ratios of most used social media platforms and daily time spent on internet and mobile phones $(N=1008)$

\begin{tabular}{ll}
\hline Variables & Percent \\
\hline Whatsapp & 92 \\
Instagram & 79 \\
Youtube & 78 \\
Facebook & 55 \\
Snapchat & 37 \\
Google & 37 \\
Twitter & 32 \\
Daily internet use $(0-2$ h) & 14 \\
Daily internet use $(2-4$ h) & 41 \\
Daily internet use $(4 \mathrm{~h}$ or more $)$ & 45 \\
Daily mobile phone use $(0-2$ h) & 13 \\
Daily mobile phone use $(2-4$ h) & 35 \\
Daily mobile phone use $(4$ h or more $)$ & 52 \\
\hline
\end{tabular}

Google+ $(37 \%)$, and Twitter (32\%). Mean scores, standard deviations, and maximumminimum scores are provided in Table 2.

Summaries of zero-order correlations and multiple linear regression analyses for gender, age, and personality as predictor variables, and social media use motives as outcome variables are presented in Table 3. Analysis indicated that gender, extraversion, age, and openness to experience were associated with using social media sites for maintaining existing relationships $(\mathrm{MER})$ and the regression model explained $4 \%$ of the $\operatorname{MER}\left(F_{[7997]}=6.27 ; p<.001\right)$. Being female, young, higher extraverted, and open to experience were related to higher MER uses and gratifications. While only gender and age were associated with meeting new people and socializing (MNPS), together they explained $4 \%$ of the MNPS $\left(F_{[7997]}=7.28 ; p<.001\right)$. Being male and young were related to meeting new people and socializing gratifications. Another gratification was making, expressing, or presenting a more popular self (MEPO) and age and conscientiousness together explained $1 \%$ of the variance $\left(F_{[7997]}=2.44 ; p<.05\right)$. Being young and less conscientious were associated with usage aim of MEPO. Passing time (PT) was another use motive and being young and neurotic explained $3 \%$ of the variance $\left(F_{[7997]}=6.04\right.$; $p<.001)$. Being female and extravert were associated with social media being a task management tool $\left(F_{[7997]}=5.20 ; p<.001\right)$. Younger and extraverted students used social media for entertainment and together explained $2 \%$ of the variance $\left(F_{[7997]}=3.22 ; p<.01\right)$. Finally,

Table 2 Mean scores, standard deviations, and minimum, maximum scores on the variables of social media use $(N=1008)$

$M E R$ maintaining existing relationships; MNPS meet new people and socializing; $M E P O$ make, express, or present more popular oneself; PT pass time; ATMT as a task management tool; $E N T$ entertainmental; IAE informational and educational

\begin{tabular}{lllrl}
\hline & Min & Max & \multicolumn{1}{l}{ M } & SD \\
\hline Problematic social media use & 0 & 36 & 15.21 & 7.48 \\
Extraversion & 2 & 10 & 6.84 & 2.01 \\
Agreeableness & 2 & 10 & 7.20 & 1.46 \\
Conscientiousness & 3 & 10 & 7.84 & 1.33 \\
Neuroticism & 2 & 10 & 6.08 & 2.14 \\
Openness to experience & 2 & 10 & 7.84 & 1.65 \\
MER & 4 & 20 & 13.72 & 3.48 \\
MNPS & 4 & 20 & 9.12 & 3.64 \\
MEPO & 4 & 20 & 7.64 & 2.97 \\
PT & 3 & 15 & 10.62 & 2.82 \\
ATMT & 5 & 25 & 14.15 & 4.71 \\
ENT & 4 & 20 & 12.40 & 3.72 \\
IAE & 6 & 30 & 21.78 & 4.81 \\
\hline
\end{tabular}




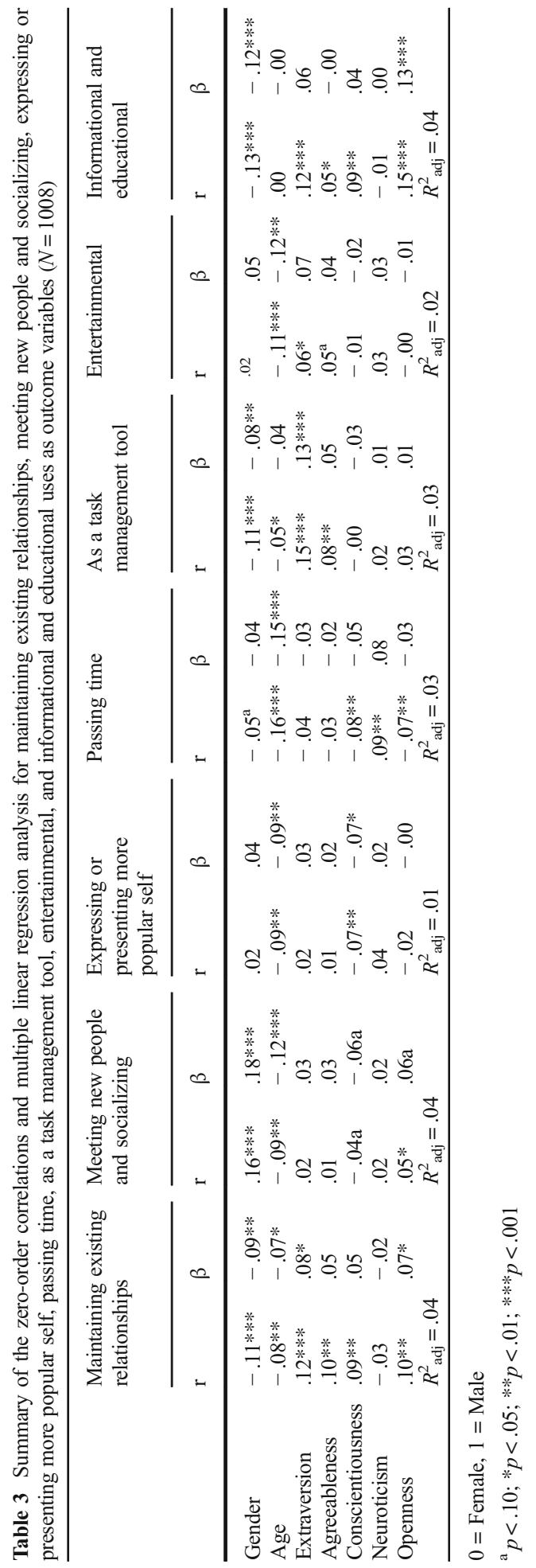


being female and open to experience were weakly associated with informational and educational (IAE) use of social media and predicted $4 \%$ of the variance $\left(F_{[7997]}=7.08 ; p<.001\right)$.

Summaries of zero-order correlations and multiple linear regression analyses for gender, age, and social media use motives as predictor variables and different SMS use as outcome variables are presented in Table 4 . While being male and older were positively associated with Facebook use $\left(F_{[9995]}=6.90 ; p<.001\right)$, gratification of maintaining existing relationships was related to Whatsapp use $\left(F_{[9995]}=2.48 ; p<.01\right)$. Expressing or presenting a more popular self and informational and educational gratifications were associated with higher Twitter use $\left(F_{[9995]}=3.90 ; p<.001\right)$. Instagram use $\left(F_{[9995]}=13.15 ; p<.001\right)$ was negatively associated with age and positively with passing time and expressing or presenting a more popular self. Being female and expressing or presenting a more popular self-motive were related to higher Snapchat use $\left(F_{[9995]}=6.24 ; p<.001\right)$. Finally, Youtube use $\left(F_{[9995]}=5.56 ; p<.001\right)$ was negatively associated with being female and expressing or presenting a more popular self, and positively with passing time and entertainment. Older female participants reported higher Google+ use $\left(F_{[9995]}=3.62 ; p<.001\right)$.

Finally, hierarchical regression analysis was applied with gender, age, personality traits, most used social media platforms, and social media use motives as predictor variables and PSMU as a criterion variable (Table 5). Passing time $(\beta=.27, p<.001)$ was moderately associated with PSMU, and gender $(\beta=-.19, p<.001)$, maintaining existing relationships $(\beta=.12, p<.001)$, meeting new people and socializing $(\beta=.12, p<.001)$, neuroticism $(\beta=.10, p<.001)$, Instagram use $(\beta=.10, p<.001)$, Snapchat use $(\beta=.08, p<.01)$, agreeableness $(\beta=.06, p<.05)$, extraversion $(\beta=-.08, p<.01)$, entertainmental use $(\beta=.08$, $p<.05)$, informational and educational use $(\beta=-.07, p<.05)$, Facebook use $(\beta=.06, p$ $<.05)$, and conscientiousness $(\beta=-.06, p<.05)$ were weakly associated with PSMU.

Total variance of PSMU explained by the final model was $27 \%, F_{(21,983)}=18.48 ; p<.001$. More specifically, unique explanation of the variance of PSMU by gender and age was $4 \%$, by personality traits was $4 \%$, by most used social media platforms was $7 \%$, and by social media use motives was $13 \%$. In summation, those with higher levels of PSMU were more likely to be female, agreeable, introverted, neurotic, and non-conscientiousness. They were also more likely to use Instagram, Snapchat, and Facebook. Their motivations for SMS use were most likely to be passing time, meeting new people and socializing, expressing or presenting a more popular self, entertainment, and lower information and education motives.

\section{Discussion}

The present study used U\&GT framework to examine the relationship between social media use motives and problematic social media use (PSMU) among Turkish undergraduates, while controlling for demographics, personality traits, and popular social media sites (SMSs). Multiple linear regression analyses were performed in terms of gender, age, and personality traits as independent variables, and social media use motives as outcome variables. Also, analyses in terms of gender, age, and social media use motives as independent variables and SMSs use as outcome variable were also carried out. Additionally, hierarchical regression analysis was performed in terms of gender, age, personality traits, most commonly used SMSs, and social media use motives as independent variables, and PSMU as the dependent variable.

The results showed that compared to males, females used social media significantly more for maintaining existing relationships, managing their tasks, and for informational and 


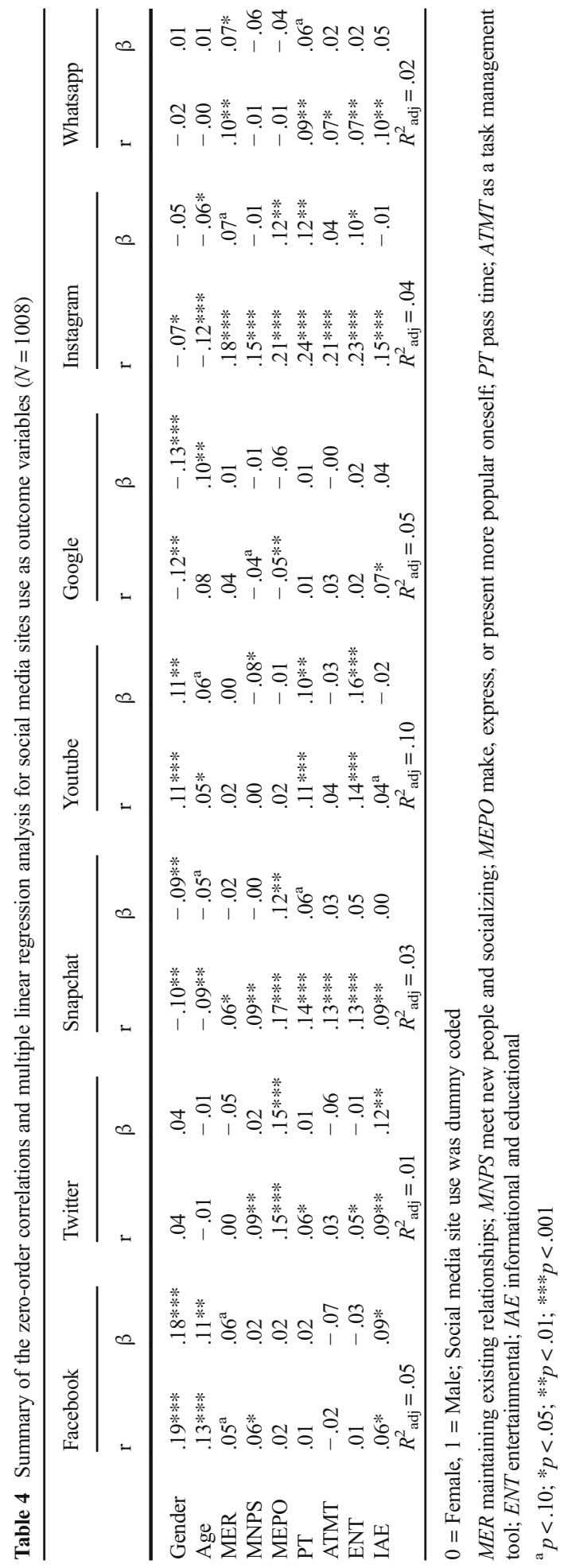


Table 5 Summary of zero-order correlations and hierarchical regression analysis with problematic social media use as outcome variable $(N=1008)$

\begin{tabular}{|c|c|c|c|c|c|}
\hline & \multirow[t]{2}{*}{$r$} & \multicolumn{4}{|l|}{$\beta(t)$} \\
\hline & & Block 1 & Block 2 & Block 3 & Block 4 \\
\hline Demographics & \multicolumn{5}{|c|}{$R_{\text {Change }}^{2}=.04 ; R_{\text {adj }}^{2}=.04 ; F_{(2,1002)}=19.88 ; p<.001$} \\
\hline Gender & $-.17 * * *$ & $\begin{array}{r}-.15 \\
\quad(-4.9\end{array}$ & $-.16(-4.98 * * *)$ & $-.15(-4.84 * * *)$ & $-.19(-6.35 * * *)$ \\
\hline Age & $-.12 * * *$ & $\begin{array}{l}-.10 \\
\quad(-3.2\end{array}$ & $-.09(-2.91 * *)$ & $-.01(-.41)$ & $-.01(-.21)$ \\
\hline Personality & \multicolumn{5}{|c|}{$R_{\text {Change }}^{2}=.04 ; R_{\text {adj }}^{2}=.07 ; F_{(7.997)}=11.66 ; p<.001$} \\
\hline Extraversion & -.03 & & $-.06(-1.99 *)$ & $-.06(-2.04 *)$ & $-.07\left(-2.46^{*}\right)$ \\
\hline Agreeableness & $.06 *$ & & $.08\left(2.61^{* *}\right)$ & $.08(2.81 * *)$ & $.07(2.47 *)$ \\
\hline Conscientiousness & $-.10 * * *$ & & $-.09(-2.70 * *)$ & $-.05(-1.64)$ & $-.06(-1.98 *)$ \\
\hline Neuroticism & $.15^{* * * *}$ & & $.15(4.85 * * *)$ & $.12\left(4.26^{* * *}\right)$ & $.10\left(3.66^{* * *}\right)$ \\
\hline Openness & $-.06^{*}$ & & $-.00(-.10)$ & $.01(.32)$ & $.01(.34)$ \\
\hline Social media platforms & \multicolumn{5}{|c|}{$R_{\text {Change }}^{2}=.07 ; R_{\text {adj }}^{2}=.14 ; F_{(14,990)}=12.58 ; p<.001$} \\
\hline Facebook & .03 & & & $.06(2.05 *)$ & $.06\left(2.06^{*}\right)$ \\
\hline Whatsapp & $.08 * *$ & & & $.02(.53)$ & $.03(1.06)$ \\
\hline Twitter & $.10 * * *$ & & & $.07(2.34 *)$ & $.04(1.54)$ \\
\hline Instagram & $.25 * * *$ & & & $.18(6.01 * * *)$ & $.10\left(3.38^{* * *}\right)$ \\
\hline Snapchat & $.20 * * *$ & & & $.14(4.34 * * *)$ & $.08\left(2.90^{* *}\right)$ \\
\hline Youtube & .02 & & & $.00(.01)$ & $-.03(-.92)$ \\
\hline Google & -.01 & & & $.02(.52)$ & $.01(.76)$ \\
\hline Social media use motives & \multicolumn{5}{|c|}{$R_{\text {Change }}^{2}=.13 ; R_{\text {adj }}^{2}=.27 ; F_{(21,983)}=18.48 ; p<.001$} \\
\hline MER & $.11 * * *$ & & & & $-.06\left(-1.83^{\mathrm{a}}\right)$ \\
\hline MEPO & $.25 * * *$ & & & & $.12(3.68 * * *)$ \\
\hline MNPS & $.30 * * *$ & & & & $.12\left(3.55^{* * *}\right)$ \\
\hline PT & $.39 * * *$ & & & & $.27\left(8.30^{* * *}\right)$ \\
\hline ATMT & $.21 * * *$ & & & & $-.01(-.30)$ \\
\hline ENT & $.25 * * *$ & & & & $.08(2.12 *)$ \\
\hline IAE & $.12 * * *$ & & & & $-.07(-2.06 *)$ \\
\hline
\end{tabular}

$0=$ Female, 1 = Male; social media site use was dummy coded

$M E R$ maintaining existing relationships; MNPS meet new people and socializing; $M E P O$ make, express, or present more popular oneself; $P T$ pass time; $A T M T$ as a task management tool; ENT entertainmental; IAE informational and educational

${ }^{\mathrm{a}} p<.10 ; * p<.05 ; * * p<.01 ; * * * p<.001$

educational gratifications. These findings are consistent with previous studies which have asserted that women have more actual friends on Facebook than men (Moore and McElroy 2012), and that women use Facebook for informational and educational gratifications (Horzum 2016). It may be the case that women are significantly more active than men in maintaining ties with close friends, using social media to get social information on their friends, maintaining networks, and for self-enhancement (Krasnova et al. 2017). Previous research has also demonstrated that women share less information about themselves and they are more worried about their online security; therefore, they are more goal-oriented when it comes to using social media (Horzum 2016).

In the present study, women were more likely than men to be problematic users of social media. This finding is consistent with previous studies (Andreassen et al. 2017; Griffiths et al. 2014; Kircaburun et al. 2018a, b). Also, previous studies suggest that women spend more time on Facebook and Instagram, share more videos on Youtube, upload more selfies, and comment or post "likes" on others' selfies to a greater extent than men (Choi et al. 2017; Khan 2017; 
Moore and McElroy 2012; Sheldon and Bryant 2016; Sorokowska et al. 2016; Sorokowski et al. 2016). This is arguably because women are more prone to become addicted to activities involving social interaction (Andreassen et al. 2013). These findings support the fact that women use social media more problematically than men.

On the other hand, men tend to use social media for meeting new people and for socializing. This result concurs with prior studies reporting higher use of Facebook for meeting new people and socializing among men (Horzum 2016). This result may be explained by the supporting findings of previous studies which suggest that using Facebook for the social gratifications is related to higher eveningness (i.e., having a preference for getting up later and going to bed later) (Horzum and Demirhan 2017), and that higher eveningness is associated higher flirtatious behaviors and having more sexual partners on the part of men (Piffer 2010; Piffer et al. 2011). Moreover, eveningness has been associated with the Dark Triad of personality (Jonason et al. 2013; Rahafar et al. 2017) which has also been associated with a faster lifestyle and short-term mating on the part of men (Jonason et al. 2009). Based on these studies, it might be that men use social media as a dating strategy for finding short-term sexual partners.

Age is another important demographic feature when considering PSMU and social media use motives. Findings in the present study showed that being younger was positively related to all social media use motives except as a task management tool and for informational and educational gratifications. This finding may be supported by those studies that have indicated an increasing frequency of selfie uploads and edits (Kim and Chock 2017; Sorokowski et al. 2016), higher online disclosure (Misoch 2015), and higher use of Snapchat (Grieve 2017) by younger individuals. The result may also be explained by the different generations that participated in the present study. According to the categorization made by the Center For Generational Kinetics (TCGK 2016), while $23 \%$ of the participants in the present study are Millennials, $77 \%$ belong to Generation Z (iGen). Most of the members of iGen do not recall a time before social media, and are prone to live most of their lives online and via smartphones (TCGK 2016). Consequently, they are much more involved with social media uses and gratifications compared to Millennials.

In terms of personality, extraversion was found to be positively related with social media use for maintaining existing relationships and for managing tasks. In addition, introverts were more likely to use social media problematically. This finding is consistent with a crosssectional study that reported higher usage of Facebook as a task management tool on the part of extraverts (Horzum 2016), as well as with a systematic review that noted a positive association between extraversion and higher usage of social media for the social consolidation of existing relationships (Kuss and Griffiths 2011). Extraverts have higher number of general and actual friends and group memberships (Bachrach et al. 2012; Kim and Chock 2017; Moore and McElroy 2012), post more status updates and selfies (Bachrach et al. 2012; Sorokowska et al. 2016), are more socially active on social media by posting more comments and "likes" on others' selfies, and demonstrate a greater amount of self-disclosure (Choi et al. 2017; Misoch 2015). Despite extraverts' higher levels of social activities, introverts engage in more PSMU than extraverts. This finding may be explained by the fact that introverts have lower self-esteem (Erdle et al. 2009) and higher loneliness (Cheng and Furnham 2002). While loneliness is related negatively to active social contributions and positively to passive engagement, shyness is positively associated with passive engagement and negatively associated with real-time social interaction (Ryan and Xenos 2011). As much as introverts spend excessive amounts of time on social media, they do not share many selfies or make status updates in 
order to avoid negative comments as a way of preserving their level of self-esteem. They may use their time on social media mostly by checking out other individuals' profiles without any interaction to avoid real life struggles and social interactions.

Another personality dimension that was related to social media use motives and PSMU was conscientiousness. Conscientious students demonstrated lower scores on the social media gratification of expressing or presenting a more popular self. Posting self-related materials on Facebook, and feeling less regret about those posts, have been related to lower conscientiousness in previous studies (e.g., Moore and McElroy 2012). Since they tend to be less organized, unambitious, emotionally driven, and inconsistent (Costa and McCrae 2000), unconscientious students may be less successful in life and unpopular among their peers. Therefore, they may use social media to present a more successful, superior, and better version of themselves. Consequently, such self-promotion efforts by unconscientious individuals may result in excessive and problematic social media use.

In the present study, neuroticism was found to be related to social media uses and gratifications of passing time and to PSMU. Neurotics are emotionally unstable individuals who tend to be impulsive, get angry quickly, and perceive life negatively (McCrae and John 1992). Therefore, it is unsurprising that they have difficulties pursuing real life social relationships and have difficulties in coping with life. Instead, they may want to escape from their real life by occupying themselves with excessive social media use. Neurotic individuals have been reported to involve themselves more in social media activities such as liking others' posts (Bachrach et al. 2012), blogging (Guadagno et al. 2008), active social contributions, and passive engagement by following fan pages and different groups (Ryan and Xenos 2011). Neurotic individuals also have relatively few friends (Bachrach et al. 2012), involve themselves in others' comments on their selfies (Choi et al. 2017), spend more time on Facebook, and regret the things they have shared more (Moore and McElroy 2012).

Openness to experience was not related to PSMU. However, students who were open to experience tended to use social media more for maintaining their existing relationships and for informational and educational gratifications. Individuals who are open to experience tend to be curious, imaginative, original, and to have a wide range of interests (McCrae and John 1992). They are likely to use favorable features of new technologies for easing their lives, and for facilitating broader social relationships. In addition, since using social media enables individuals to search and reach for information and for educational materials by getting millions of people together to interact and contribute, it is a much more subtle way to find needed information and educational sources. Previous studies report that students who are more open to new experiences follow more groups on social media (Bachrach et al. 2012).

With regard to social media platforms, Instagram and Snapchat were the second and fifth most commonly used SMSs among students. Instagram was positively related to presenting a more popular self, passing time and entertainment gratifications, and PSMU. Snapchat was associated with PSMU and expressing or presenting more popular self-gratifications. These findings are consistent with a previous study which reported higher intensity of social media on Instagram and Snapchat compared to Facebook and Twitter (Alhabash and Ma 2017). Using image-based social media platforms involving sharing photos and videos makes interaction and communication more intimate and realistic (Pittman and Reich 2016). Consequently, Instagram and Snapchat use decreases loneliness and increases happiness and satisfaction with life when compared to other social media platforms. Moreover, using Instagram and Snapchat has been positively related to self-documentation, entertainment, and self-expression uses and gratifications (Alhabash and Ma 2017). The main reasons for using of Instagram have been found to be 
surveillance, documentation, coolness, and creativity (Sheldon and Bryant 2016). Instagram appears to have become one of the most important social networking platforms of recent times by meeting all kinds of users' different needs, and by increasing feelings of intimacy and happiness, especially among young people. Regarding Snapchat, as opposed to the present study, students have mainly reported using Snapchat for maintaining close relationships with close friends and family (Piwek and Joinson 2016). However, the "best friends list" feature of Snapchat has been associated with higher degrees of jealousy in interpersonal relationships and which may be harmful among close friends (Vaterlaus et al. 2016). Instagram and Snapchat use were also both related to higher PSMU among student in the present study. This result may be explained by the positive associations Instagram and Snapchat uses have with uses and gratifications linked to PSMU which are expressing or presenting a more popular self and passing time. Also, editing and posting selfies have been positively related to a higher amount of time spent on social media in previous studies (e.g., Kim and Chock 2017).

Facebook was the fourth most commonly used social media platform among the participants of the present study, and higher Facebook use was related to higher social media uses of informational and educational gratifications and PSMU. This finding is partially consistent with a recent study which reported a positive association between Facebook use and keeping up with distant and close friends, information and education, passing time, and self-promotion (Sendurur et al. 2015). The results are also parallel to another study which indicated that most students use Facebook for social motives, while others use it for educational gratifications by creating groups and exchanging course-related information (Manasijević et al. 2016). Previous research has also indicated that there is a positive association between Facebook use for educational gratification and academic achievement (Lambić 2016). Facebook, which is one of the oldest social media platforms and has the highest number of active users worldwide (Kemp 2017a, b), can be considered as a practical platform for gaining information and education gratifications by using a wide range of different established groups.

Twitter was the seventh most commonly used social media platform in present study, and was significantly related to the social media uses and gratifications of expressing and presenting a more popular self, and for information and education gratifications. Previous studies have reported that many factors (i.e., higher levels of cognition, conscientiousness, introversion, lower neuroticism, lower sociability, and for reading celebrity and entertainment news) are related to a higher preference for Twitter use for information gratifications (Hargittai and Litt 2011; Hughes et al. 2012).

Regarding the relationship between social media use motives and PSMU, when controlling for demographics, personality, and social media sites, passing time was the strongest predictor of PSMU. It appears that students who use social media to pass time when they have nothing to do are more likely to experience PSMU. Also, meeting new people and socializing by using social media and uses of social media for expressing or presenting a more popular self significantly positively influences students' levels of PSMU. This may be because narcissistic individuals are more addicted to social media out of their efforts to make themselves look better than who they really are and to present better self-image (Andreassen et al. 2017). Narcissists also use social media for social gratifications and their social media profiles are really important for them (Błachnio et al. 2016). It may be that uses and gratifications that are rooted in narcissistic impulses may lead to higher PSMU.

The present study is not without its limitations. Firstly, it used only self-report measures. In future studies, mixed methods may be used in order to gain further insights into the relationships between variables studied here. Secondly, the study sample comprised Turkish university 
students. Therefore, to generalize the results, other more nationally representative samples from Turkey and other countries must be included in future studies. Thirdly, the cross-sectional nature of the study makes it impossible to indicate causal affects and relationships between variable studies. Finally, only demographic data regarding gender and age were collected from the participants. Future studies will need to examine different demographic features of participants (e.g., religion, political ideology, marital status, employment status, etc.) and their associations with preferences of social media use and problematic social media use.

Despite its limitations, the present study has a couple of strong novel and distinctive features. First, the study is the first, to the best of the authors' knowledge, that has simultaneously examined the relationship between Turkish university students' most commonly used social media platforms, social media use motives, and PSMU. Second, the study provides greater evidence to the literature regarding associations between gender, age, personality, and PSMU.

\section{Conclusion}

Findings of the present study indicated that women use social media more for maintaining their existing relationships, as a task management tool, and for informational and educational purposes, while men use social media more for meeting new people, for socializing, and for entertainment. Younger students use social media more for maintaining their existing relationships, for meeting new people, for socializing, for expressing or presenting themselves as being more popular, for passing time, and for entertainment. Moreover, while women show a higher preference for Snapchat and Google+ use, men prefer Facebook and YouTube. Instagram use was more prevalent among younger participants and Facebook and Google+ use was more prevalent for older participants.

Regarding personality, extraverted individuals use social media more for maintaining their existing relationships, for passing time, and for managing their tasks. Less conscientious individuals use social media more for expressing or presenting themselves as being more popular. Neurotic individuals use social media more for passing time. Finally, individuals who were open to experience use social media more for maintaining their existing relationships and for informational and educational purposes.

Regarding the most commonly used social media platforms, Instagram use was significantly related to expressing or presenting a more popular self, passing time, and entertainment motives. Snapchat use was related to expressing or presenting more popular self-motive. Facebook use was related to informational and educational gratifications. Whatsapp was associated with maintaining existing relationships. Twitter was related to expressing or presenting a more popular self-motive, and for informational and educational gratifications. Finally, Youtube was positively related to passing time and entertainment and negatively related to meeting new people and socializing.

PSMU was associated with a number of demographic and personality factors including being female, being introverted, being more agreeable, being neurotic, and being less conscientious. In relation to social media platform, PSMU was associated with higher use of Instagram, Snapchat, and Facebook. In relation to motives, PSMU was positively associated with meeting new people and socializing, expressing or presenting a more popular self, and passing time, and negatively associated with informational and educational uses.

The present study examined the inter-relationships between demographics, personality traits, popular SMSs, social media use motives, and PSMU in a comprehensive way. This is 
important because most studies have only examined the variables here in relation to just one social media platform (typically Facebook). The present study contributes to the understanding of the role of social media use motives on the preferences of many different popular social media sites, as well as the role of popular social media sites and social media use motives in the development of problematic social media use while controlling for demographics and personality.

\section{Compliance with Ethical Standards}

Conflict of Interest The authors declare that they do not have any interests that could constitute a real, potential, or apparent conflict of interest with respect to their involvement in the publication. The authors also declare that they do not have any financial or other relations (e.g., directorship, consultancy, or speaker fee) with companies, trade associations, unions or groups (including civic associations and public interest groups) that may gain or lose financially from the results or conclusions in the study. Sources of funding are acknowledged.

Ethical Approval All procedures performed in this study involving human participants were in accordance with the ethical standards of University's Research Ethics Board and with the 1975 Helsinki Declaration.

Informed Consent Informed consent was obtained from all participants.

Open Access This article is distributed under the terms of the Creative Commons Attribution 4.0 International License (http:/creativecommons.org/licenses/by/4.0/), which permits unrestricted use, distribution, and reproduction in any medium, provided you give appropriate credit to the original author(s) and the source, provide a link to the Creative Commons license, and indicate if changes were made.

\section{References}

Alexa (2017). The top 500 sites on the web. Retrieved April 1, 2018, from: https://www.alexa.com/topsites.

Alhabash, S., \& Ma, M. (2017). A tale of four platforms: Motivations and uses of Facebook, Twitter, Instagram, and Snapchat among college students? Social Media+ Society. https://doi.org/10.1177/2056305117691544.

Alhabash, S., Chiang, Y. H., \& Huang, K. (2014). MAM \& U\&G in Taiwan: Differences in the uses and gratifications of Facebook as a function of motivational reactivity. Computers in Human Behavior, 35, 423430.

Allport, G. (1961). Pattern and growth in personality. New York: Holt, Rinehart, \&Winston.

Amichai-Hamburger, Y., \& Vinitzky, G. (2010). Social network use and personality. Computers in Human Behavior, 26(6), 1289-1295.

Andreassen, C. S., Torsheim, T., Brunborg, G. S., \& Pallesen, S. (2012). Development of a Facebook addiction scale. Psychological Reports, 110(2), 501-517.

Andreassen, C. S., Griffiths, M. D., Gjertsen, S. R., Krossbakken, E., Kvam, S., \& Pallesen, S. (2013). The relationships between behavioral addictions and the five-factor model of personality. Journal of Behavioral Addictions, 2(2), 90-99.

Andreassen, C. S., Pallesen, S., \& Griffiths, M. D. (2017). The relationship between addictive use of social media, narcissism, and self-esteem: Findings from a large national survey. Addictive Behaviors, 64, 287293.

Bachrach, Y., Kosinski, M., Graepel, T., Kohli, P., \& Stillwell, D. (2012, June). Personality and patterns of Facebook usage. In Proceedings of the 4th Annual ACM Web Science Conference (pp. 24-32). New York: Association for Computer Machinery.

Balakrishnan, J., \& Griffiths, M. D. (2017). Social media addiction: What is the role of content in YouTube? Journal of Behavioral Addictions, 6(3), 364-377.

Bányai, F., Zsila, Á., Király, O., Maraz, A., Elekes, Z., Griffiths, M. D., et al. (2017). Problematic social media use: Results from a large-scale nationally representative adolescent sample. PLOS ONE, 12(1), e0169839.

Beaton, D. E., Bombardier, C., Guillemin, F., \& Ferraz, M. B. (2000). Guidelines for the process of cross-cultural adaptation of self-report measures. Spine, 25, 3186-3191. 
Błachnio, A., Przepiorka, A., \& Rudnicka, P. (2016). Narcissism and self-esteem as predictors of dimensions of Facebook use. Personality and Individual Differences, 90, 296-301.

Boyd, D. M., \& Ellison, N. B. (2007). Social network sites: Definition, history, and scholarship. Journal of Computer-Mediated Communication, 13(1), 210-230.

Burgess, J., \& Green, J. (2009). YouTube: digital media and society series. Cambridge: Polity.

Center For Generational Kinetics (2016). Top 10 Gen Z questions answered. Retrieved April 1, 2018, from: http://genhq.com/igen-gen-Z-generation-Z-centennials-info/.

Chen, G. M. (2011). Tweet this: A uses and gratifications perspective on how active Twitter use gratifies a need to connect with others. Computers in Human Behavior, 27(2), 755-762.

Chen, H. T., \& Kim, Y. (2013). Problematic use of social network sites: The interactive relationship between gratifications sought and privacy concerns. Cyberpsychology, Behavior, and Social Networking, 16(11), 806-812.

Cheng, H., \& Furnham, A. (2002). Personality, peer relations, and self-confidence as predictors of happiness and loneliness. Journal of Adolescence, 25(3), 327-339.

Choi, T. R., Sung, Y., Lee, J. A., \& Choi, S. M. (2017). Get behind my selfies: the Big Five traits and social networking behaviors through selfies. Personality and Individual Differences, 109, 98-101.

Costa, P., \& McCrae, R. (2000). Revised NEO personality inventory interpretive report. Lutz: Psychological Assessment Resources.

Curran, K., Morrison, S., \& Mc Cauley, S. (2012). Google+ vs Facebook: The comparison. TELKOMNIKA (Telecommunication Computing Electronics and Control), 10(2), 379-388.

Davenport, S. W., Bergman, S. M., Bergman, J. Z., \& Fearrington, M. E. (2014). Twitter versus Facebook: Exploring the role of narcissism in the motives and usage of different social media platforms. Computers in Human Behavior, 32, 212-220.

Duggan, M. (2013). Photo and video sharing grow online. In Pew research internet project Retrieved April 1, 2018, from: http://www.pewinternet.org/2013/10/28/photo-and-video-sharing-grow-online/.

Erdle, S., Gosling, S. D., \& Potter, J. (2009). Does self-esteem account for the higher-order factors of the Big Five? Journal of Research in Personality, 43(5), 921-922.

Facebook (2017). Two billion people coming together on Facebook. Retrieved April 1, 2018, from: https://newsroom.fb.com/news/2017/06/two-billion-people-coming-together-on-facebook/.

Floros, G., \& Siomos, K. (2013). The relationship between optimal parenting, internet addiction and motives for social networking in adolescence. Psychiatry Research, 209(3), 529-534.

Google+ (2017). About Google+. Retrieved April 1, 2018, from: https://plus.google.com/about?hl=tr.

Gosling, S. D., Rentfrow, P. J., \& Swann, W. B. (2003). A very brief measure of the Big-Five personality domains. Journal of Research in Personality, 37(6), 504-528.

Grieve, R. (2017). Unpacking the characteristics of Snapchat users: A preliminary investigation and an agenda for future research. Computers in Human Behavior, 74, 130-138.

Griffiths, M. (2005). A 'components' model of addiction within a biopsychosocial framework. Journal of Substance Use, 10(4), 191-197.

Griffiths, M. D. (2010). The role of context in online gaming excess and addiction: Some case study evidence. International Journal of Mental Health and Addiction, 8(1), 119-125.

Griffiths, M. D. (2014). Child and adolescent social gaming: What are the issues of concern? Education and Health, 32, 9-12.

Griffiths, M. D. (2015). Adolescent gambling and gambling-type games on social networking sites: Issues, concerns, and recommendations. Aloma: Revista de Psicologia, Ciències de l'Educació i de l'Esport, 33(2), 31-37.

Griffiths, M. D., Kuss, D. J., \& Demetrovics, Z. (2014). Social networking addiction: An overview of preliminary findings. In K. Rosenberg \& L. Feder (Eds.), Behavioral addictions: Criteria, evidence and treatment (pp. 119-141). New York: Elsevier.

Guadagno, R. E., Okdie, B. M., \& Eno, C. A. (2008). Who blogs? Personality predictors of blogging. Computers in Human Behavior, 24(5), 1993-2004.

Gunel, Ö. D. (2010). Mobbing in organizations and a research on mobbing victims' personality characteristics. Dokuz Eylül University Social Science Institute. Journal, 12, 37-65.

Hargittai, E., \& Litt, E. (2011). The tweet smell of celebrity success: Explaining variation in Twitter adoption among a diverse group of young adults. New Media \& Society, 13(5), 824-842.

Haridakis, P., \& Hanson, G. (2009). Social interaction and co-viewing with YouTube: Blending mass communication reception and social connection. Journal of Broadcasting \& Electronic Media, 53(2), 317-335.

Hong, F. Y., Huang, D. H., Lin, H. Y., \& Chiu, S. L. (2014). Analysis of the psychological traits, Facebook usage, and Facebook addiction model of Taiwanese university students. Telematics and Informatics, 31(4), 597-606.

Horzum, M. B. (2016). Examining the relationship to gender and personality on the purpose of Facebook usage of Turkish university students. Computers in Human Behavior, 64, 319-328. 
Horzum, M. B., \& Demirhan, E. (2017). The role of chronotype on Facebook usage aims and attitudes towards Facebook and its features. Computers in Human Behavior, 73, 125-131.

Hou, J., Ndasauka, Y., Jiang, Y., Ye, Z., Wang, Y., Yang, L., Li, X., Zhang, Y., Pang, L., Kong, Y., Xu, F., \& Zhang, X. (2017). Excessive use of WeChat, social interaction and locus of control among college students in China. PLoS One, 12(8), e0183633.

Hu, L. T., \& Bentler, P. M. (1999). Cutoff criteria for fit indexes in covariance structural analysis: Conventional criteria versus new alternatives. Structural Equation Modelling, 6(1), 1-55.

Huang, H. (2011). Social media addiction among adolescents in urban China: An examination of sociopsychological traits, uses and gratifications, academic performance, and social capital. Doctoral dissertation, Chinese University of Hong Kong.

Hughes, D. J., Rowe, M., Batey, M., \& Lee, A. (2012). A tale of two sites: Twitter vs. Facebook and the personality predictors of social media usage. Computers in Human Behavior, 28(2), 561-569.

Instagram (2017). About us. Retrieved April 1, 2018, From: https://www.instagram.com/about/us/.

Jackson, C. A., \& Luchner, A. F. (2017). Self-presentation mediates the relationship between self-criticism and emotional response to Instagram feedback. Personality and Individual Differences. https://doi.org/10.1016/j. paid.2017.04.052.

Johnson, P. R., \& Yang, S. (2009). Uses and gratifications of twitter: An examination of user motives and satisfaction of twitter use. Paper presented at the annual meeting of the Association for Education in journalism and mass communication, Boston, MA.

Jonason, P. K., Li, N. P., Webster, G. D., \& Schmitt, D. P. (2009). The dark triad: Facilitating a short-term mating strategy in men. European Journal of Personality, 23(1), 5-18.

Jonason, P. K., Jones, A., \& Lyons, M. (2013). Creatures of the night: Chronotypes and the dark triad traits. Personality and Individual Differences, 55(5), 538-541.

Junco, R. (2013). Comparing actual and self-reported measures of Facebook use. Computers in Human Behavior, 29(3), 626-631.

Karapanos, E., Teixeira, P., \& Gouveia, R. (2016). Need fulfillment and experiences on social media: A case on Facebook and WhatsApp. Computers in Human Behavior, 55, 888-897.

Katz, J. E., \& Crocker, E. T. (2015). Selfies and photomessaging as visual conversation: Reports from the United States, United Kingdom, \& China. International Journal of Communication, 9, 1861-1872.

Katz, E., Blumler, J. G., \& Gurevitch, M. (1973). Uses and gratifications research. Public Opinion Quarterly, 37(4), 509-523.

Kemp, S. (2017a). Digital in 2017: Global overview. Retrieved April 1, 2018, from: http://wearesocial. com/uk/blog/2017/01/digital-in-2017-global-overview.

Kemp, S. (2017b). Digital in 2017: Global overview. Retrieved April 1, 2018, from: https://wearesocial. com/special-reports/digital-in-2017-global-overview.

Khan, M. L. (2017). Social media engagement: What motivates user participation and consumption on YouTube? Computers in Human Behavior, 66, 236-247.

Kim, J. W., \& Chock, T. M. (2017). Personality traits and psychological motivations predicting selfie posting behaviors on social networking sites. Telematics and Informatics, 34(5), 560-571.

Kim, E. J., Namkoong, K., Ku, T., \& Kim, S. J. (2008). The relationship between online game addiction and aggression, self-control and narcissistic personality traits. European Psychiatry, 23(3), 212-218.

Kircaburun, K. (2016a). Effects of gender and personality differences on twitter addiction among Turkish undergraduates. Journal of Education and Practice, 7(24), 33-42.

Kircaburun, K. (2016b). Self-esteem, daily internet use and social media addiction as predictors of depression among Turkish adolescents. Journal of Education and Practice, 7(24), 64-72.

Kircaburun, K., \& Griffiths, M. (2018a). Instagram addiction and the big five of personality: the mediating role of self-liking. Journal of Behavioral Addictions, 7(1), 158-170.

Kircaburun, K., \& Griffiths, M. (2018b). Problematic Instagram use: The role of perceived feeling of presence and escapism. International Journal of Mental Health and Addiction, in press.

Kircaburun, K., Demetrovics, Z., \& Tosuntaș, Ș. B. (2018a). Analyzing the links between problematic social media use, dark triad traits and self-esteem. International Journal of Mental Health and Addiction, 1-12. https://doi.org/10.1007/s11469-018-9900-1.

Kircaburun, K., Kokkinos, C. M., Demetrovics, Z., Király, O., Griffiths, M. D., \& Çolak, T. S. (2018b). Problematic online behaviors among adolescents and emerging adults: Associations between cyberbullying perpetration, problematic social media use and psychosocial factors. International Journal of Mental Health and Addiction, in press.

Koc, M., \& Gulyagci, S. (2013). Facebook addiction among Turkish college students: The role of psychological health, demographic, and usage characteristics. Cyberpsychology, Behavior, and Social Networking, 16(4), 279-284. 
Krasnova, H., Veltri, N. F., Eling, N., \& Buxmann, P. (2017). Why men and women continue to use social networking sites: The role of gender differences. Journal of Strategic Information Systems, 26, 261-284.

Krause, A. E., North, A. C., \& Heritage, B. (2014). The uses and gratifications of using Facebook music listening applications. Computers in Human Behavior, 39, 71-77.

Kuss, D. J., \& Griffiths, M. D. (2011). Online social networking and addiction-A review of the psychological literature. International Journal of Environmental Research and Public Health, 8(9), 3528-3552.

Kuss, D. J., \& Griffiths, M. D. (2017). Social networking sites and addiction: Ten lessons learned. International Journal of Environmental Research and Public Health, 14, 311.

Lambić, D. (2016). Correlation between Facebook use for educational purposes and academic performance of students. Computers in Human Behavior, 61, 313-320.

Lee, E., Lee, J. A., Moon, J. H., \& Sung, Y. (2015). Pictures speak louder than words: Motivations for using Instagram. Cyberpsychology, Behavior, and Social Networking, 18(9), 552-556.

Liu, I. L. B., Cheung, C. M. K., \& Lee, M. K. O. (2010). Understanding twitter usage: What drive people continue to tweet. In PACIS 2010 proceedings (p. 92). Pacific Asia Conference on Information Systems: Kaohsiung, Taiwan.

Manasijević, D., Živković, D., Arsić, S., \& Milošević, I. (2016). Exploring students’ purposes of usage and educational usage of Facebook. Computers in Human Behavior, 60, 441-450.

Marino, C., Vieno, A., Pastore, M., Albery, I. P., Frings, D., \& Spada, M. M. (2016). Modeling the contribution of personality, social identity and social norms to problematic Facebook use in adolescents. Addictive Behaviors, 63, 51-56.

McCrae, R. R., \& John, O. P. (1992). An introduction to the five-factor model and its applications. Journal of Personality, 60(2), 175-215.

McCrae, R. R., Costa Jr., P. T., Del Pilar, G. H., Rolland, J. P., \& Parker, W. D. (1998). Cross-cultural assessment of the five-factor model: The revised NEO personality inventory. Journal of Cross-Cultural Psychology, 29(1), 171-188.

Misoch, S. (2015). Stranger on the internet: Online self-disclosure and the role of visual anonymity. Computers in Human Behavior, 48, 535-541.

Moore, K., \& McElroy, J. C. (2012). The influence of personality on Facebook usage, wall postings, and regret. Computers in Human Behavior, 28(1), 267-274.

Nadkarni, A., \& Hofmann, S. G. (2012). Why do people use Facebook? Personality and Individual Differences, 52(3), 243-249.

Papacharissi, Z., \& Rubin, A. M. (2000). Predictors of internet use. Journal of Broadcasting \& Electronic Media, 44(2), 175-196.

Piffer, D. (2010). Sleep patterns and sexual selection: An evolutionary approach. Mankind Quarterly, 50(4), 361375.

Piffer, D., Gunawardane, K. C., \& Custance, D. M. (2011). Evidence of sexual selection for evening orientation in human males: A cross cultural study in Italy and Sri Lanka. Interdisciplinary Bio Central, 3(4), 13.1-13.8.

Pittman, M., \& Reich, B. (2016). Social media and loneliness: Why an Instagram picture may be worth more than a thousand Twitter words. Computers in Human Behavior, 62, 155-167.

Piwek, L., \& Joinson, A. (2016). "What do they snapchat about?" Patterns of use in time-limited instant messaging service. Computers in Human Behavior, 54, 358-367.

Punyanunt-Carter, N. M., De La Cruz, J. J., \& Wrench, J. S. (2017). Investigating the relationships among college students' satisfaction, addiction, needs, communication apprehension, motives, and uses \& gratifications with Snapchat. Computers in Human Behavior, 75, 870-875.

Quan-Haase, A., \& Young, A. L. (2010). Uses and gratifications of social media: A comparison of Facebook and instant messaging. Bulletin of Science, Technology \& Society, 30(5), 350-361.

Rahafar, A., Randler, C., Castellana, I., \& Kausch, I. (2017). How does chronotype mediate gender effect on dark triad? Personality and Individual Differences, 108, 35-39.

Rubin, A. M. (1993). Audience activity and media use. Communications Monographs, 60(1), 98-105.

Ryan, T., \& Xenos, S. (2011). Who uses Facebook? An investigation into the relationship between the Big Five, shyness, narcissism, loneliness, and Facebook usage. Computers in Human Behavior, 27(5), 1658-1664.

Ryan, T., Chester, A., Reece, J., \& Xenos, S. (2014). The uses and abuses of Facebook: A review of Facebook addiction. Journal of Behavioral Addictions, 3(3), 133-148.

Satici, S. A. (2018). Facebook addiction and subjective well-being: A study of the mediating role of shyness and loneliness. International Journal of Mental Health and Addiction, 1-15. https://doi.org/10.1007/s11469017-9862-8.

Sendurur, P., Sendurur, E., \& Yilmaz, R. (2015). Examination of the social network sites usage patterns of preservice teachers. Computers in Human Behavior, 51, 188-194.

Sheldon, P., \& Bryant, K. (2016). Instagram: motives for its use and relationship to narcissism and contextual age. Computers in Human Behavior, 58, 89-97. 
Smock, A. D., Ellison, N. B., Lampe, C., \& Wohn, D. Y. (2011). Facebook as a toolkit: a uses and gratification approach to unbundling feature use. Computers in Human Behavior, 27(6), 2322-2329.

Sorokowska, A., Oleszkiewicz, A., Frackowiak, T., Pisanski, K., Chmiel, A., \& Sorokowski, P. (2016). Selfies and personality: Who posts self-portrait photographs? Personality and Individual Differences, 90, 119-123.

Sorokowski, P., Sorokowska, A., Frackowiak, T., Karwowski, M., Rusicka, I., \& Oleszkiewicz, A. (2016). Sex differences in online selfie posting behaviors predict histrionic personality scores among men but not women. Computers in Human Behavior, 59, 368-373.

Stanley, B. (2015). Uses and gratifications of temporary social media: a comparison of Snapchat and Facebook. Fullerton, CA: California State University.

Statista. (2018). Number of monthly active Twitter users worldwide from 1st quarter 2010 to 4th quarter 2017 (in millions). Retrieved April 1, 2018. In From https:/www.statista.com/statistics/282087/number-of-monthlyactive-twitter-users/.

Utz, S., Muscanell, N., \& Khalid, C. (2015). Snapchat elicits more jealousy than Facebook: A comparison of Snapchat and Facebook use. Cyberpsychology, Behavior, and Social Networking, 18(3), 141-146.

Vaterlaus, J. M., Barnett, K., Roche, C., \& Young, J. A. (2016). "Snapchat is more personal": An exploratory study on Snapchat behaviors and young adult interpersonal relationships. Computers in Human Behavior, 62, 594-601.

Wagner, K. (2015). Instagram is the fastest growing major social network. Retrieved April 1, 2018, from: https://www.recode.net/2015/1/9/11557626/instagram-is-the-fastest-growing-major-social-network.

Wan, C. (2009). Gratifications \& loneliness as predictors of campus-SNS websites addiction \& usage pattern among Chinese college students. Master's Thesis, Chinese University of Hong Kong.

WhatsApp (2017). About WhatsApp. Retrieved April 1, 2018, from: https:/www.whatsapp.com/about/?l=en.

Whiting, A., \& Williams, D. (2013). Why people use social media: A uses and gratifications approach. Qualitative Market Research, 16(4), 362-369.

Xanidis, N., \& Brignell, C. M. (2016). The association between the use of social network sites, sleep quality and cognitive function during the day. Computers in Human Behavior, 55, 121-126.

Xu, W. W., Park, J. Y., Kim, J. Y., \& Park, H. W. (2016). Networked cultural diffusion and creation on YouTube: An analysis of YouTube memes. Journal of Broadcasting \& Electronic Media, 60(1), 104-122.

Young, K. (2015). The evolution of internet addiction disorder. In C. Montag \& M. Reuter (Eds.), Internet addiction, studies in neuroscience, psychology, and behavioral economics (pp. 3-17). New York: Springer.

Zhao, W. X., Jiang, J., Weng, J., He, J., Lim, E.-P., Yan, H., \& Li, X. (2011). Comparing Twitter and traditional media using topic models. In P. Clough, C. Foley, C. Gurrin, G. J. F. Jones, W. Kraaij, H. Lee, \& V. Mudoch (Eds.), Advances in information retrieval (pp. 338-349). New York: Springer. 